\title{
Cardiovascular risk factors in a population of Brazilian schoolchildren
}

A.N. Rodrigues ${ }^{1,2}$, M.R. Moyses ${ }^{1}$, N.S. Bissoli ${ }^{1,2}$, J.G.P. Pires ${ }^{1}$ and G.R. Abreu ${ }^{1,2}$

\author{
${ }^{1}$ Departamento de Ciências Fisiológicas, Centro de Ciências da Saúde, \\ Universidade Federal do Espírito Santo, Vitória, ES, Brasil \\ ${ }^{2}$ Faculdade Salesiana de Vitória, Vitória, ES, Brasil
}

Correspondence

G.R. Abreu

Centro de Ciências da Saúde, UFES

Av. Marechal Campos, 1468

29042-755 Vitória, ES

Brasil

Fax: +55-27-3335-7330

E-mail: grabreu@npd.ufes.br

E.................

Received January 17, 2006 Accepted August 23, 2006

\begin{abstract}
Epidemiological and clinical evidence suggests that a judicious diet, regular physical activity and blood pressure (BP) monitoring must start in early childhood to minimize the impact of modifiable cardiovascular risk factors. This study was designed to evaluate BP and metabolic parameters of schoolchildren from Vitória, Espírito Santo State, Brazil, and correlate them with cardiovascular risk factors. The study was conducted on 380 students aged 10-14 years (177 boys, 203 girls) enrolled in public schools. Baseline measurements included body mass index, BP and heart rate. The students were submitted to exercise spirometry on a treadmill. $\mathrm{VO}_{2 \max }$ was obtained from exercise testing to voluntary exhaustion. Fasting serum total cholesterol (TC), LDL-C, HDL-C, triglycerides (TG), and glucose were measured. Nine point nine percent of the boys and $11.7 \%$ of the girls were hypertensive or had pre-hypertensive levels. There was no significant correlation between $\mathrm{VO}_{2 \max }$ and TC, LDL-C, or TG in prepubertal children, but a slight negative correlation was detected in post-pubertal boys for HDL-C and TG. In addition, children with hypertension (3.4\%) or prehypertensive levels $(6.6 \%)$ also had comorbidity for overweight and blood lipid abnormalities (14\% for triglycerides, $44.7 \%$ for TC, $25.9 \%$ for LDL-C, $52 \%$ for low HDL-C). The present study shows for the first time high correlations between prehypertensive blood pressure levels and the cardiovascular risk factors high TC, high LDL-C, low HDL-C in schoolchildren. These are important for the formulation of public health policies and strategies.
\end{abstract}

\section{Introduction}

Although the idea that atherosclerosis begins in infancy was proposed as early as in 1914 , only in the last decade was it recognized as a pediatric problem (1). Clinical and epidemiological studies have suggested that periodic blood pressure (BP) and biochemical determinations in schoolchildren permit the early detection of risk factors and treat-
Key words

- Cardiovascular risk factors

- Arterial hypertension

- Primary prevention

- Coronary artery disease

- Obesity

- Schoolchildren 
children, are predictive of coronary disease. Thus, early detection of such risk factors can be crucial to establish prognosis and to prevent target-organs damage in adulthood $(3,4)$. Although the clinical manifestations of hypertension and coronary disease occur in adulthood, the primary prevention of such conditions should start in childhood $(3,4)$.

For practical and epidemiological reasons, childhood represents a good opportunity for studies regarding the detection/prevention of modifiable cardiovascular risk factors, including sedentary lifestyle, hypercaloric food intake and overweight/obesity. If initiated during early childhood, appropriate changes in lifestyle patterns should be able to reduce the later incidence and severity of cardiovascular diseases $(4,5)$. Despite the existence of published studies dealing with the prevalence of cardiovascular risk factors and/or the correlation among atherosclerosis risk factors in Brazil (6-8), population studies in schoolchildren in our region are lacking. Therefore, the present study was designed to evaluate the metabolic profile (e.g., serum lipids, glucose, etc.) and the aerobic fitness of schoolchildren (including adolescents) from a population in the Vitória area, Eastern Brazil, looking for correlations

Table 1. General characteristics of the schoolchildren enrolled in the study. Vitória, ES, Brazil, 2005.

\begin{tabular}{|c|c|c|}
\hline Parameter & Boys & Girls \\
\hline Age (years) & $12.6 \pm 1.48$ & $12.4 \pm 1.41$ \\
\hline BMI $\left(\mathrm{kg} / \mathrm{m}^{2}\right)$ & $18.2 \pm 3.37$ & $18.7 \pm 3.37$ \\
\hline $\mathrm{VO}_{2 \max }\left(\mathrm{mL} \mathrm{kg}{ }^{-1} \mathrm{~min}^{-1}\right)$ & $45.5 \pm 8.41$ & $37.9 \pm 5.94^{*}$ \\
\hline Heart rate $(\mathrm{bpm})$ & $76 \pm 9$ & $81 \pm 9$ \\
\hline Systolic blood pressure $(\mathrm{mmHg})$ & $107 \pm 11$ & $108 \pm 9$ \\
\hline Diastolic blood pressure $(\mathrm{mmHg})$ & $63 \pm 7$ & $64 \pm 7$ \\
\hline Fasting glucose (mg/dL) & $82.7 \pm 7.43$ & $81.3 \pm 6.93$ \\
\hline Triglycerides (mg/dL) & $70.4 \pm 32$ & $77.5 \pm 29$ \\
\hline Total cholesterol (mg/dL) & $150.9 \pm 27$ & $151.3 \pm 29$ \\
\hline LDL-C (mg/dL) & $91.4 \pm 23$ & $91.2 \pm 27$ \\
\hline $\mathrm{HDL}-\mathrm{C}(\mathrm{mg} / \mathrm{dL})$ & $45.4 \pm 10$ & $44.6 \pm 8$ \\
\hline
\end{tabular}

The study group was composed of 177 boys and 203 girls. BMI = body mass index; $\mathrm{VO}_{2 \max }=$ maximal oxygen consumption; LDL-C $=$ LDL-cholesterol; HDL-C $=\mathrm{HDL}-$ cholesterol.

${ }^{*} \mathrm{P}<0.05$ compared to boys (Student $t$-test). between risk factors and arterial hypertension.

\section{Subjects, Material and Methods}

Schoolchildren aged 10-14 years (177 boys and 203 girls) enrolled in all the public schools of Vitória city, were randomly allocated to this cross-sectional study. Data were collected between March 2003 and March 2005. The study was approved by the Ethics Committee of Faculdade Salesiana de Vitória and written parental consent was obtained in all cases, after the parents were informed of the purpose of the investigation, procedures, benefits, and risks.

Data initially obtained by standard methods were age at the time of the study (years, presented in decimal format), body weight $(\mathrm{kg})$, and height $(\mathrm{m})$. Body mass index (BMI) was then calculated from body weight and height and expressed as $\mathrm{kg} / \mathrm{m}^{2}$. The criteria established in 1995 by the WHO (9), in 2000 by Cole et al. (10), and in 2005 by Daniels et al. (11) were used to determine the conditions of thinness, overweight and obesity. Sexual maturity was assessed by the occurrence of menarche in girls and by the presence of axillary hair in boys $(12,13)$.

Students were interviewed about their lifestyle and family history of cardiovascular diseases and assessed for cardiovascular parameters and exercise capacity. Children were then submitted to standard ECG, from which heart rate was determined. Resting arterial BP was measured using a mercury sphygmomanometer with appropriate arm cuff length; the average of three determinations was used. Criteria for classification as normotensive, borderline or hypertensive took into account BP values for the 90th and 95th percentiles. Thus, values below the 90th percentile were considered normotensive and values above the 95th percentile were considered hypertensive (14-17). To determine aerobic capacity based on maximal oxygen consumption $\left(\mathrm{VO}_{2 \max }\right)$, the schoolchildren 
were submitted to ergospirometry $\left(\mathrm{CardiO}_{2}\right.$, MedGraphics Co., St. Paul, MN, USA) on a treadmill. $\mathrm{VO}_{2 \max }$ was obtained from exercise testing to voluntary exhaustion (18). A cardiac defibrillator and adequate resuscitation equipment were available at all times during the procedures.

Fasting serum glucose, triglycerides, total cholesterol (TC), LDL-C, and HDL-C were determined using conventional laboratory enzymatic and colorimetric techniques. The reference ranges applied were based on international (19) and Brazilian (20) standards, as follows: serum glucose $70-110 \mathrm{mg}$ / $\mathrm{dL}$, triglycerides $>100 \mathrm{mg} / \mathrm{dL}, \mathrm{TC}>150 \mathrm{mg} /$ $\mathrm{dL}$, LDL-C $>100 \mathrm{mg} / \mathrm{dL}$, and HDL-C $\geq 45$ $\mathrm{mg} / \mathrm{dL}$.

Unless otherwise stated, data are presented as means \pm SEM. The Student $t$-test was used for comparison between two means and the chi-square test or odds-ratio determination was used for multiple proportion comparisons, as appropriate. When appropriate, linear regression was performed or Pearson's correlation coefficients were calculated. In all cases, the level of significance was set at $\mathrm{P}<0.05$.

\section{Results}

Among the 177 boys and 203 girls enrolled in this study, 38.4 and $45.8 \%$, respectively $(\mathrm{P}<0.05)$, were sexually mature. The mean age of the schoolchildren was 12.6 and 12.4 years, for boys and girls, respectively, with no significant difference between genders. Table 1 shows these and the other general characteristics of the study sample. It can be seen that there was no statistically significant difference between boys and girls regarding the variables studied, except for $\mathrm{VO}_{2 \max }$, as expected from the literature (e.g., Ref. 18).

We classified $9.6 \%$ of the boys and $7.4 \%$ of the girls as overweight, and 6.2 and $4.9 \%$ as obese, respectively (Table 2). Regarding resting $\mathrm{BP}$ values, hypertension was detected in $3.4 \%$ of both boys and girls, taking into account values above the 90th percentile. Borderline high BP was detected in $5.1 \%$ of the boys and $7.9 \%$ of the girls. Increased serum cholesterol was found in about $20 \%$ of the children, regardless of gender. In addition, almost $50 \%$ of the schoolchildren had abnormally decreased HDL-C values. The differences between boys and girls regarding the risk factors under study were not statistically significant (data summarized in Table 2).

Correlation coefficients $(r)$ between the levels of each serum lipid parameter and blood pressure, both systolic and diastolic, were also determined. In this analysis, the students were classified as "before" or "after" sexual maturation. Only in the pre-pubertal girls subgroup was a significant positive correlation detected between serum lipid parameters and blood pressure $(r=0.24$, $\mathrm{P}=0.039$ ).

Table 3 shows the $r$ values for correlation between each serum lipid level and $\mathrm{VO}_{2 \max }$ and BMI for boys and girls. Similar correlation coefficients were determined between systolic and diastolic arterial pressure and the same two parameters, namely $\mathrm{VO}_{2 \max }$ and BMI. The schoolchildren were divided

Table 2. Prevalence of cardiovascular risk factors in a sample of schoolchildren from Vitória, ES, Brazil.

\begin{tabular}{lrr}
\hline Risk factor & Boys & \multicolumn{1}{c}{ Girls } \\
\hline Overweight & $9.6 \%$ & $7.4 \%$ \\
Obesity & $6.2 \%$ & $4.9 \%$ \\
Borderline hypertension & $5.1 \%$ & $7.9 \%$ \\
Hypertension & $3.4 \%$ & $3.4 \%$ \\
Borderline triglycerides & $6.8 \%$ & $11.8 \%$ \\
Increased triglycerides & $3.4 \%$ & $5.9 \%$ \\
Borderline total cholesterol & $24.9 \%$ & $24.6 \%$ \\
Increased total cholesterol & $19.2 \%$ & $20.7 \%$ \\
Borderline LDL-C & $18.1 \%$ & $20.7 \%$ \\
Increased LDL-C & $5.7 \%$ & $7.4 \%$ \\
Decreased HDL-C & $56.5 \%$ & $47.8 \%$ \\
& &
\end{tabular}

The differences between 177 boys and 203 girls for these factors were not statistically significant (confidence interval for odds ratios). LDL-C = LDLcholesterol; HDL-C = HDL-cholesterol. 
into two categories, concerning sexual maturation (Table 3). Among the boys, there were statistically significant inverse correlations between $\mathrm{VO}_{2 \max }$ and TC and triglycerides, but only in the post-pubertal students. In addition, among the post-pubertal boys BMI correlated positively with TC, LDL-C, and systolic and diastolic BP. Among the girls, the only significant correlation between $\mathrm{VO}_{2 \max }$ and the measured parameters was detected with serum triglycerides in the prepubertal subgroup; nevertheless, it was a very small correlation $(r=0.08, \mathrm{P}>0.05)$. In addition, BMI positively correlated with systolic arterial pressure in both pre- $(r=0.24$, $\mathrm{P}=0.02)$ and post-pubertal $(r=0.47, \mathrm{P}=$ $0.005)$ girls. Serum glucose levels were within the normal range in both sexes, with girls and boys exhibiting similar values (82 \pm 6 vs $78 \pm 7 \mathrm{mg} / \mathrm{dL}$ ).

\section{Discussion}

The present results characterize a particular epidemiological condition in a population of 10-14-year-old Brazilian schoolchildren. Since such population studies are relatively scarce in Brazil, the present results can provide important information for the

\begin{tabular}{|c|c|c|c|c|c|c|c|c|}
\hline & \multicolumn{4}{|c|}{$\mathrm{VO}_{2 \max }$} & \multicolumn{4}{|c|}{ BMI } \\
\hline & \multicolumn{2}{|c|}{ Boys } & \multicolumn{2}{|c|}{ Girls } & \multicolumn{2}{|c|}{ Boys } & \multicolumn{2}{|c|}{ Girls } \\
\hline & Before & After & Before & After & Before & After & Before & After \\
\hline Cholesterol & -0.02 & $-0.33^{*}$ & -0.09 & -0.04 & -0.02 & 0.23 & 0.00 & -0.12 \\
\hline HDL-C & 0.08 & 0.09 & -0.07 & 0.02 & 0.02 & $-0.32^{*}$ & -0.16 & -0.17 \\
\hline LDL-C & -0.05 & $-0.29^{*}$ & -0.09 & -0.03 & -0.05 & $0.33^{*}$ & 0.02 & -0.09 \\
\hline Triglycerides & -0.00 & $-0.36^{*}$ & 0.07 & -0.08 & 0.05 & 0.22 & 0.13 & 0.04 \\
\hline Systolic BP & 0.09 & -0.11 & 0.01 & -0.09 & 0.09 & $0.44^{*}$ & 0.16 & $0.35^{*}$ \\
\hline Diastolic BP & 0.00 & -0.15 & 0.01 & -0.08 & 0.00 & 0.22 & 0.04 & 0.12 \\
\hline
\end{tabular}

Values are correlation coefficients $(r) . \mathrm{VO}_{2 \max }=$ maximal oxygen consumption; $\mathrm{BMI}=$ body mass index; "Before" and "After" = before or after sexual maturation; LDL-C = LDL-cholesterol; HDL-C = HDL-cholesterol; $\mathrm{BP}=$ blood pressure. ${ }^{*} \mathrm{P}<0.05$ (Fisher test). region's public health policy. The overall occurrence of overweight or obesity was about $13.9 \%$ for the schoolchildren, a level that, although slightly lower than those reported for the United States (21), Europe (22) and some other regions of Brazil $(6,23)$, suggests that obesity among children is elevated, and might become a public health problem in the Vitória city area. In a study by Guimarães and Guimarães (8) conducted in Salvador, BA, the prevalence of overweight/obesity among 6-12-year-old schoolchildren was similar to that reported here. This is an important issue in view of the association between obesity and heart diseases and stroke (24).

Total serum cholesterol was high in about $20 \%$ of the schoolchildren studied. This figure is slightly lower than those observed in other Brazilian urban areas (25-27). As shown in Table 3, a limited number of significant correlations are demonstrable between some biochemical markers and BMI among boys, but not among girls. These gender differences have been reported by others $(1,28)$ and could be due to gonadal hormone influence, although the molecular mechanisms involved are not understood.

The significant correlation detected between BMI and systolic pressure among the girls (Table 3 ) also deserves mention, since, to our knowledge, this has not been described before. It remains to be proved if the hemodynamic consequences of obesity are involved in this association. It seems that gonadal influences do not account for this effect, since correlation between obesity and hypertension was observed in both sexes (Table 3).

The present results showing hypertriglyceridemia in about $4 \%$ and hypertension + borderline BP in about $12 \%$ of the schoolchildren irrespective of gender, agree with most of the data from the Brazilian and international literature (21-28). However, our data showing that about $1 / 5$ of the students have increased LDL-C represent higher val- 
ues than those reported in other studies (2128 ), possibly reflecting local nutritional aspects, which also deserve further investigation.

An interesting result was the correlation observed between maximal oxygen consumption and some serum lipids (Table 3), for which we have no explanation.

Our results regarding schoolchildren in Vitória also show that the prevalence of borderline hypertension + hypertension is lower than the rates reported in other similar Brazilian studies $(29,30)$. This difference could be due to our lower levels of over- weight + obesity (as suggested by the correlation detected between BMI and BP), although other factors cannot be ruled out.

The present data provide a general picture of our population of schoolchildren in terms of cardiovascular risk factors and their association with arterial pressure. It is expected that such data may be useful for the implementation of preventive strategies during childhood, including the control of conditions such as overweight, borderline hypertension and dyslipidemia, which could help early prevention of cardiovascular diseases.

\section{References}

1. Strong WB, Kelder SH. Pediatric preventive cardiology. In: Manson JE, Ridker PM, Gaziano DM, Hennekens CH (Editors), Prevention of myocardial infarction. Oxford: Oxford Univ Press; 1996. p 433459.

2. Gordon T, Castelli WP, Hjortland MC, Kannel WB, Dawber TR. High density lipoprotein as a protective factor against coronary heart disease. The Framingham Study. Am J Med 1977; 62: 707-714.

3. Akerblom HK, Viikari J, Kouvalainen K. Cardiovascular risk factors in Finnish children and adolescents. Acta Paediatr Scand Suppl 1985; 318: 5-6.

4. Armstrong N, Balding J, Gentle P, Kirby B. Estimation of coronary risk factors in British schoolchildren: a preliminary report. Br J Sports Med 1990; 24: 61-66.

5. Massin M, Vandoorne C, Coremans C, Lepage P, Scheen A. Preventive cardiology: strategies in children. Rev Med Liege 2002; 57: 207-212.

6. Coronelli CL, de Moura EC. Hypercholesterolemia and its risk factors among schoolchildren. Rev Saude Publica 2003; 37: 24-31.

7. Soar C, Vasconcelos FAG, Assis MAA. Waist-hip ratio and waist circumference associated with body mass index in a study with schoolchildren. Cad Saude Publica 2004; 20: 1609-1616.

8. Guimarães IC, Guimarães AC. Prevalence of cardiovascular risk factors in selected samples of schoolchildren - socioeconomic influence. Prev Cardiol 2005; 8: 23-28.

9. WHO. Physical status: the use and interpretation of anthropometry. Report of a WHO Expert Committee. World Health Organ Tech Rep Ser 1995; 854: 1-452.

10. Cole TJ, Bellizzi MC, Flegal KM, Dietz WH. Establishing a standard definition for child overweight and obesity worldwide: international survey. BMJ 2000; 320: 1240-1243.

11. Daniels SR, Arnett DK, Eckel RH, Gidding SS, Hayman LL, Kumanyika S, et al. Overweight in children and adolescents: pathophysiology, consequences, prevention, and treatment. Circulation 2005; 111: 1999-2012.

12. Duarte MFS. Maturação física: uma revisão da literatura, com especial atenção à criança brasileira. Cad Saude Publica 1993; 9: 71-84.

13. Monteiro PO, Victora CG, Barros FC, Tomasi E. Diagnosis of over- weight in adolescents: comparative study of the performance different criteria for body mass index. Rev Saude Publica 2000; 34: 506-513.

14. Williams CL, Hayman LL, Daniels SR, Robinson TN, Steinberger J, Paridon S, et al. Cardiovascular health in childhood: A statement for health professionals from the Committee on Atherosclerosis, Hypertension, and Obesity in the Young (AHOY) of the Council on Cardiovascular Disease in the Young, American Heart Association. Circulation 2002; 106: 143-160.

15. Salgado CM, Carvalhaes JT. Arterial hypertension in childhood. $J$ Pediatr 2003; 79 (Suppl 1): S115-S124.

16. Sociedade Brasileira de Cardiologia. IV Diretrizes Brasileiras de Hipertensão Arterial. Revista da Sociedade Brasileira de Hipertensão 2002; 4: 360-408

17. Zahka KG. Report of the Second Task Force on the Blood Pressure Control in Children. Pediatrics 1993; 79: 1-25.

18. Karila C, de Blic J, Waernessyckle S, Benoist MR, Scheinmann P. Cardiopulmonary exercise testing in children: an individualized protocol for workload increase. Chest 2001; 120: 81-87.

19. Kwiterovich PO Jr. Plasma lipid and lipoprotein levels in childhood. Ann N Y Acad Sci 1991; 623: 90-107.

20. Sociedade Brasileira de Cardiologia. I Diretriz de Prevenção da Aterosclerose na Infância e Adolescência. Arq Bras Cardiol 2005; 85: 1-36.

21. Edmunds L, Waters E, Elliott EJ. Evidence based paediatrics: Evidence based management of childhood obesity. BMJ 2001; 323: 916-919.

22. Eckel RH, York DA, Rossner S, Hubbard V, Caterson I, St Jeor ST, et al. Prevention Conference VII: Obesity, a worldwide epidemic related to heart disease and stroke: executive summary. Circulation 2004; 110: 2968-2975.

23. Giugliano R, Melo AL. Diagnosis of overweight and obesity in schoolchildren: utilization of the body mass index international standard. $J$ Pediatr 2004; 80: 129-134.

24. Freedman DS, Dietz WH, Srinivasan SR, Berenson GS. The relation of overweight to cardiovascular risk factors among children and adolescents: the Bogalusa Heart Study. Pediatrics 1999; 103: 11751182 . 
25. Moura EC, de Castro CM, Mellin AS, de Figueiredo DB. Lipid profile among school children in Campinas, Brazil. Rev Saude Publica 2000; 34: 499-505.

26. Gerber ZR, Zielinsky P. Risk factors for atherosclerosis in children: an epidemiologic study. Arq Bras Cardiol 1997; 69: 231-236.

27. Giuliano IC, Coutinho MS, Freitas SF, Pires MM, Zunino JN, Ribeiro RQ. Serum lipids in school kids and adolescents from Florianópolis, SC, Brazil - Healthy Floripa 2040 study. Arq Bras Cardiol 2005; 85: 85-91.
28. Tolfrey K, Campbell IG, Jones AM. Selected predictor variables and the lipid-lipoprotein profile of prepubertal girls and boys. Med Sci Sports Exerc 1999; 31: 1550-1557.

29. Oliveira RG, Lamounier JA, Oliveira AD, Castro MD, Oliveira JS. Blood pressure in school children and adolescents - The Belo Horizonte study. J Pediatr 1999; 75: 256-266.

30. Moura AA, Silva MA, Ferraz MR, Rivera IR. Prevalence of high blood pressure in children and adolescents from the city of Maceió, Brazil. J Pediatr 2004; 80: 35-40. 